\title{
On study of professional sociolect as language universalia
}

\author{
Ekaterina Dvorak ${ }^{1, *}$ \\ ${ }^{1}$ Irkutsk State National Research Technical University, Department of foreign languages, 664074, Irkutsk, Russia
}

\begin{abstract}
The concept of a "professional sociolect" is considered in the paper in terms of a sociolinguistic approach. A definition is given to the language phenomenon under consideration. Sociolect is studied as a complex of a language unique features that are characteristic for some of the social group. The concept is being studied with the purpose of its structure and base components specification. The basic categories of the language phenomenon under consideration have been accentuated within the specification offered. The influence of professional sociolects on the people's everyday utterance and their degree of stabilization in the literary canons of the national language has been also investigated by the authors. The professional sociolect of oil and gas engineers was taken as an example.
\end{abstract}

\section{Introduction}

The study of a language social differentiation resulting, among other things, in the formation of sociolects allows one to follow in the most vivid and clear way the interconnection between the language and society and is the most important task of sociolinguistics. Taking into consideration the effect produced by professional languages on the development of the nation-wide language, which is an ingress of new linguistic units into the common language usage or some changes in the already existing ones, the study of professional sociodialects, in our opinion, is acquiring still greater importance with the modern science.

The post analysis of research literature allows acknowledging the fact that the investigations of the colloquial language in the social way came into being with regard to the native study of a language comparatively before long - in the years of 20-30, 20th century. It was in that period that the term of "social dialect" first appeared in the science, the scientific field of sociolinguistics coming into being in linguistics. A language started to be considered in a close interrelation with the social processes running in the society. In the scientific works by R.I. Avanesov, L.I. Barannikov, V.I. Borkovskiy, N.P. Grinkov, A.P. Yevgenyev, V.I. Sobinnikov, F.P. Filin, etc. The functioning of sociolects has been investigated with the focus mainly on social characteristics of a speaker. They were those investigations that became foundational ones for the development of social dialectology as a science studying the process of a language development and its social differentiation. Thus, it has become a tradition to speak about the use of language units within territorial or social groups.
Following the linguistic traditions of everyday speech studies held within social dialectology, T.I. Yerofeyeva, as an investigator into the problem, was the first who introduced the term of "sociolect". From the author's point of view, on the one hand, the above-mentioned category includes the notion of a social type, an individual demonstrating it under the influence of features specific for a certain race, ethnic group, nationality, social class. In other words, this is the utterance of a "common subject". On the other hand, sociolect recognizes also a system of speech facilities belonging to a certain group and being determined with a number of factors that have not only social but also biological and psychological characters (e.g. sex, age, temperament, etc.) [1]. The analysis of scientific literature performed allows one to note that the concept of "sociolect" has not been studied completely for today and does not provide an opportunity to formulate a single universal definition of the given concept.

Some of the investigators, including V.I. Belikov and L.P. Krysin, give rather a narrow definition of the concept under investigation. On the evidence of the above-mentioned authors, a sociolect is a certain "complex of a language unique features that are characteristic for some of the social group: professional, stratification, age within this or that subsystem of a national language" [2]. The investigators are of the opinion that the utterance of soldiers, schoolchildren, convicts as well as different professional and commercial slangs (etc.) can be acknowledged as examples of sociodialects. Thus, we have arrived to the conclusion that, as it is realized by Krysin and Belikov, the sign of equality can be placed between a sociolect and a jargon. In their opinion, sociodialect is neither a system nor a subsystem of a language but is just different from it in separate words, word combinations and syntactic constructions.

\footnotetext{
* Corresponding author: *k-dvorak@yandex.ru
} 
Some other investigators, S.S. Polskaya and T.I. Yerofeyeva being among them, declare themselves in favor of the definition quoted in the Dictionary of Sociolinguistic Terms: "Sociolect is a variety of a language which is characteristic for its use within a certain social group, be it stratification, professional or age one"[3]. As it is added by S.S. Polskaya, a sociolect is a "relatively steady, open, organized language subsystem which is structured in a hierarchical way" [4]. Besides, basing on the author's opinion, "sociolects represent independent systems because each organic part of a natural language is constructed and developed, first of all, according to the laws that are common with regard to the whole language system and simultaneously are different in their regular transformations".

\section{Materials and methods}

Having given the consideration to these two approaches to the definition of a sociolect notion we see it reasonable to give a complete definition combining all the aspects of sociolect studies. Sociolect is a peculiar language intended for a certain social group. It developed on the basis of the national language but has some units in its structure, that are conditioned by a number of territory, social (profeccional ones including) biopsychological factors. Sociolects do not represent any integral systems of communication. The main body of the sociolect is expressed by lexical and grammar systems of the given national language, whereas its unique character is represented in speech specific for a certain group that uses it.

Within the context of the present publication, the concept of "a professional sociolect is to be given some consideration to with the aim of its structure and basic components specification.

The papers by Russian native scientists in the field of sociolinguistics provided our investigation with a theoretical basis (V.D. Bondaletov, B.A. Larin, V.M. Zhirmunskiy, L.P. Krysin, V.M. Leichik, A.V. Superanskaya, L.B. Tkachyova, etc.). In our investigation we also referred to the concepts made by scientists belonging to different sociolinguistic schools whose point of view with regard to typological classification of the sociolect has been represented. It should be mentioned that Y. Filipets in his works sets professional slang, group slang and jargon in opposition to each other; B. Tema identifies professional speech, group slang and private utterance, argo and vulgar tongue being assigned to the private utterance. In accordance with the theory by Ya. Chlowpek, professional speech, slang and argo should be differentiated. In our opinion, the following notions should be distinguished: the jargon that usually expresses its professional appliance whereas the argo can be used without any professional implication. Not infrequently, the language of declassed groups in a society is meant when argo is concerned, i.e. the language of thieves, tramps and beggars. Argo is not differentiated as an independent language system. It is meant to be specifically used as language units taken from the existing language. Argo is jargon and vulgar tongue interrelated thus forming a special lexical layer, which is slang.

Within the context of the given paper, we hold to $\mathrm{Zh}$.A. Yefremova's classification of units entering sociolect [5]. Terms, professionalisms and professional jargon are recognized as lexical formatives of a professional sociolect. The specificity of each of the language formations mentioned can be caused by both professional and social isolation of certain groups from the remaining society. In accordance with this position, it is reasonable that we should analyze in some detail each of these conceptions following the classification and definitions developed by D.E. Rosenthal.

In the dictionaries, an emotionally neutral word (word combination) is meant when we come across a "term" denoting a name of an exactly defined conception belonging to this or that field of knowledge. Terminologically marked vocabulary allows one to render the contents of an object under consideration in an exact, distinct and sparing way and to give the proper insight into a problem being rendered. So, a term is a word or a word combination exactly defining some conception in a science, technology or art, it being monosemantic and possessing no expressiveness [6]. The meaning of a term is fixed in a dictionary and this is an important distinguishing feature of a term, "the border lines of the terminological system on the whole being out-of-focus and indistinct", as it is marked by a number of authors. This is caused by several objective reasons that enable this or that word to be interpreted as a polysemantic one and, correspondingly, to refer it to this or that lexical layer [7].

"Professionalism"is a word typical of a certain professional group or the vocabulary characteristic of speaking people pertaining to one and the same profession [6]. "Jargon" is a slang word or expression common for separate social groups. It is artificially created with the purpose of linguistic isolation [6]. Jargon words often have a decreased stylistic nuance and contradict generally accepted canons of the literary language. Professionalisms and jargon words, unlike terms, can be emotionally coloured and it is possible to substitute them with some terms to make them more convenient and clear in use. Along with the above units, commonly used words in their special meanings and polysemantic words can be found in a sociolect. Such words are quite numerous although they are missing in the above classification. Therefore they should not be neglected while a professional sociolect is being analysed.

\section{Results and discussion}

In the context of the given investigation, we tried to determine the degree of a professional sociolect "sociability", i.e. to find out if it is possible for the vocabulary accounting for the basic part of professional sociolect to be used in everyday speech.

Basing on the above definitions, a suggestion was made that if a term is a special identification of a definite 
notion, its meaning is fixed in specialized dictionaries, whereas professionalisms and slang words and expressions possess some emotional nuance typical for the speech in use but unlike a term they have no clear fixation both in dictionaries of terms and in books of references. It is this very layer of lexis is able to migrate from sector-specific usage into general one.

V.V. Vinogradov's point of view [8] is of a special interest with regard to our investigation. He states that the substandard character of dialecticisms used is well pronounced and they are in too much of a contrast with the prescriptive language tradition however great were the frequency of dialecticism use, and so there is no possibility for them to acquire a literary accent. In our opinion, it does not mean that everything coming into being outside the literary language has no access to common use, colloquial language, social and professional dialects being concerned. On the contrary, the modern speech practice and some facts characteristic for the background Russian are indicative of the substandard language and jargon influencing literary speech.

For example, the word of "a double-dealer" двурушник is known to enter the standard language from the beggars' cant: initially that was how a beggar was called who was a-begging with his both hands. The word of "palpitating"- животрепещущзий has come from the speech of fishmongers, "rapid fire"скоропалительный, from army men, "chappie"топорный has been derived from carpenters professional language. Initially this was the way to characterize a carpenter's trade as a finer one and more careful as compared with the work of a cabinet-maker [5].

We support the point of view expressed by A.T. Lipatova and O.V. Nagornyak with regard to professionalisms as a component of a professional sociolect. They are characterized for a "decreased stylistic nuance", nevertheless, more than infrequently, they enter the common language use: bring to grass (mining), cramming (last minute rush), routine (every day work) [9]. In fiction, professionalisms are used by the authors having in mind a certain stylistic problems: to use professionalisms as a characterological means describing the life of people connected with some production.

Professionalisms come into being in the everyday speech of people engaged in this or that profession and form a certain language system. There are professional naming units for some objects and notions, whereas there are not any for other ones.

Naming units of a professionalism usually appear basing on metaphoric re-thinking of a certain word or a word combination and can overlap the meanings of other professionalisms. At last, as opposed to special terms, professionalisms are very specific in their expressiveness, and the mentioned feature is in contrast with an official, prescriptive, special term the meaning of which is duplicated by the given professionalism.

While analyzing linguistic units, forming the professional sociolect of uphole oilmen, we came across the following professionalisms: "dog-house" for the booth of the boring master and shift team workers; "fish" which is a noun having two meanings: 1) an object or a part of a tool left in the bore hole; 2) a foreign object [10]. While studying the materials of forums involving the representatives of oil producing field, we also came across such professionalisms as an " $X$-tree" which is a certain system of keepers used as a blowout preventer to stop a liquid from flowing. It is a piece of equipment (vaguely reminding of a tree), "slant hole" denoting a directional well, "hole making" used for a process or result of boring (the first word being a jargonism whereas the second one being a term), "pushing" is a well control equipment which is a part of a blowout preventing equipment, "rolling pin" is used to denote a unit of a well depth measurement, it being equal to a well tube in length, etc. It is evident from the examples given that the professional jargonisms considered duplicate the terms that are in common use and exist in the standard language; they are unrecognized synonyms of certain objects; they possess a well-pronounced expressive function and are a means of communication, which is characteristic of specialists, engaged in definite professional activities.

For example, in editorial offices of newspapers and magazines, the specialist selecting illustrations is called a photo editor. A photo editor is a term. However, in a real production process, it is called build (to be short) more often than not. This is professionalism, i.e. a professional jargon. Build has trampled all the pieces in the composition - there is no doubt, professionalisms are used in this sentence, not terms. If it were terms used in this case, the same phrase would sound more bulky. Besides, terms are often of another language origin, they are pronounced with difficulty and this fact also does not produce any beneficial effect on their everyday speaking use. By the way, this is why reduced forms of terms frequently become professionalisms: build-editor turns into build, whereas slide gauge (as a special sliding caliper ruler) - into caliper [11].

In some cases, professionalisms can be used as official terms; their expressivity gets somewhat less pronounced, the metaphoricalness of the meaning, which they are based on being expressed rather well. For example, $\mathrm{arm} / \mathrm{shoulder}$ of a lever, tooth of a wheel, pipe kneelelbow, etc.

Special and professional lexis having a limited sphere of use, there is a constant connection and interaction between this kind of lexis and common one. Thus, the word of "anomaly" meaning a deviation from a general regularity gradually moved from the professional terminology of medical practitioners into everyday language; the same is true for "transposition" in the meaning of displacement and a number of technical terms, such as "relevant" for essential, "local" for topical, "transformer" for converter, etc. These words do not seem to be "aliens" as they are gaining their due place in the common language use.

The definition of the common lexis offered by M.N. Peterson allows one to come to the conclusion that this is a "frame work" of a nation-wide standard vocabulary containing the basic lexical material for ideas to be 
expressed in common lexis, the reserve, first of all, facilitating further lexis perfecting and beneficiating [12]. So, beneficiating the users' standard language through accepting new lexical formatives is the function performed by a professional sociolect.

The analysis of the language material at hand allows one to make the conclusion that in some cases professionalisms tend to be used in their improper contexts, get redefined and as a result lose their term essence, that is stop being terms altogether.

Determinologization is a process turning a scientific term into a word of common use [6]. This is a process when special (professional) lexis is used in an unusual context leading to an extension of the initial meaning characteristic for lexical formatives being considered and resulting in rethinking their initial meaning. This is indicative of the fact that the above words stop their being terms to transfer from a sector-specific areola into the standard language and acquire new lexical-semantic meanings. Such scientific fields as physics, chemistry and technical spheres can also be referred to as branches characterized by determinologization of a professional (sector-specific) vocabulary. Such words as contact, resonance, synthesis, catalyst (catalyzer), apogee, coordinates, amplitude have securely taken hold of the everyday speech. It is allowed for linguistics that some of the terms "have lost their termhood... and become elements of the scientific style lexis due to their notion characteristics being out-of-focus" [13]. In accordance with this concept, we can state that such linguistic terms as metaphor, dialect, epithet, verbalize/verbify, expletives have become an integrated part of the nationwide prescriptive vocabulary.

In the context of our investigation, we were able to follow the way the concept of "professional sociolect" correlates with the notion of a "literary norm" which is one of the central linguistic notions. The term of "literary norm" is applied with regard to the varieties of the language that are used in mass media, in science and education, in diplomacy, in lawmaking and legislation as well as record keeping and legal proceedings and other spheres of "socially important" and mostly public communication [12]. If a professional sociolect is considered as a sociolinguistic phenomenon, i.e. in terms of dialectology, it is easy to notice that the use of a lower stratum lexis, such as jargon words and argo, is the main feature distinguishing it from the commonly used literary norm.

On paying special attention to the ways of professionalisms and jargon words ingressing into the everyday speech, a conclusion was made that they can be applied with regard to literature publications in their oral and written forms. Sometimes, professionalisms and jargon words can be used instead of terms in the language of a certain scientific field. However, their use in any publications is of an extraordinary, limited character. No cases of professionalism and jargon word using were registering the scientific publications whereas their sporadic use was marked in fiction as characterological devices, this use being stylistically justified.

\section{Conclusion}

The analysis performed allows making the following conclusions:

A professional sociolect is a specific language of a particular social group. It has developed on the basis of the national language and possesses linguistic units in its structure that a number of territorial and social factors (professional ones including) are responsible for. In the process of coexisting with and overlapping the literature norm of the native language, each of the professional sociolects preserves its specificity to remain an isolated and closed enough language system meant for social identification of its representatives in the sector-specific social medium. The ingress of professionalisms and jargon words into the everyday speech takes place in very rare cases as the criteria of this lexical layer do not show any agreement with the character of common lexis, this lexical layer representing linguistic units belonging to a lower speech register. Nevertheless, beneficiation of a common lexis layer in the native language takes place in the process of determinologisation of special terms that rank among a professional sociolect.

\section{References}

1. T.I. Yerofeyeva, Sociolect: stratified research. Doct. Diss. (S.-P. 1995).

2. V.I. Belikov, L.P. Krysin, Sociolinguistics. (M. RSTU. 2001.).

3. Dictionary of sociolinguistic terminology. (M.: 2006).

4. V.V. Vinogradov, The history of words. (M.: Tolk. 1994).

5. Zh.A. Yefremova, National language and social dialects. (Moscow: Russkiy yazyk. 1987).

6. D.E. Rozenthal, M.A. Telenkova, Dictionaryreference book of linguistic terms. (Moscow: Prosveshcheniye. 1985).

7. C.Yu. Pozdnyakova, Theory and technology (based on examples of sector-specific aviation terms), Selection and organization of an educational minimum wordbook. (Irkutsk National Research Technical University. Irkutsk. 2015).

8. V.V. Vinogradov, The history of words. (M.: Tolk. 1994).

9. A.D. Lipatov, Semantika i urovni yeyo realizatsii, Russian slang and its interrelation with the jargon and argo. Krasnodar. 3, 117-118, (1994).

10. I.G. Bocharova, E.V Dvorak, N.S. Druzhinina, M.I. Popova, A reference book for oil and gas specialists, Oil and gas basics. (Irkutsk. 2011).

11. V.S. Yelistratov, Russkiy yazyk za rubezhom Russian argo in the language, society and culture.. 1, 64-65, (1995).

12. M.N. Peterson, Instructional notes of the language and literature institute. Language as a social phenomenon. 1, 3-21, (1927). 
13. A.V. Lemov, System, structure and functioning of terms (basing on the material of Russian linguistic terminology). Doct.Diss. (Nizhniy Novgorod. 2000).

14. V.D. Bondaletov Social linguistics. Moscow: Prosveshcheniye. 1987, 160
15. A.Arzu, T. Issa, Procedia, Social and Behavioral Sciences, An Effect on Cultural Identity: Dialect, , 143, ,(555-562), (2014) 